Hydrol. Earth Syst. Sci., 17, 2859-2871, 2013

www.hydrol-earth-syst-sci.net/17/2859/2013/

doi:10.5194/hess-17-2859-2013

(c) Author(s) 2013. CC Attribution 3.0 License.

\title{
Drought evolution characteristics and precipitation intensity changes during alternating dry-wet changes in the Huang-Huai-Hai River basin
}

\author{
D. H. Yan ${ }^{1,2}$, D. Wu ${ }^{1,2}$, R. Huang ${ }^{1,2}$, L. N. Wang ${ }^{1,2}$, and G. Y. Yang ${ }^{1,2}$ \\ ${ }^{1}$ State Key Laboratory of Simulation and Regulation of River Basin Water Cycle, China Institute of Water Resources and \\ Hydropower Research (IWHR), Beijing, 100038, China \\ ${ }^{2}$ Water Resources Department, China Institute of Water Resources and Hydropower Research (IWHR), Beijing, \\ 100038, China
}

Correspondence to: D.Wu (wudisyau075@163.com)

Received: 27 November 2012 - Published in Hydrol. Earth Syst. Sci. Discuss.: 1 March 2013

Revised: 29 May 2013 - Accepted: 8 June 2013 - Published: 23 July 2013

\begin{abstract}
Abrupt drought-flood change events caused by atmospheric circulation anomalies have occurred frequently and widely in recent years, which has caused great losses and casualties in China. In this paper, we focus on investigating whether there will be a rainfall occurrence with higher intensity after a drought period in the Huang-Huai-Hai River basin. Combined with the Chinese climate divisions and the basin's DEM (digital elevation model), the basin is divided into seven sub-regions by means of cluster analysis of the basin meteorological stations using the self-organizing map (SOM) neural network method. Based on the daily precipitation data of 171 stations for the years 1961-2011, the changes of drought times with different magnitudes are analyzed, and the number of consecutive days without precipitation is used to identify the drought magnitudes. The first precipitation intensity after a drought period is analyzed with the Pearson-III frequency curve, then the relationship between rainfall intensity and different drought magnitudes is observed, as are the changes of drought times for different years. The results of the study indicated that the occurrence times of different drought levels show an overall increasing trend; there is no clear interdecadal change shown, but the spatial difference is significant. (2) As the drought level increases, the probability of extraordinary rainstorm becomes lower, and the frequency of occurrence of spatial changes in different precipitation intensities vary. In the areas I and II, as the drought level increases, the occurrence frequency of different precipitation intensities first shows a decreasing
\end{abstract}

trend, which becomes an increasing trend when extraordinary drought occurs. In the area III, IV and V, the probability of the different precipitation intensities shows an overall decreasing trend. The areas VI and VII are located at the mountains with high altitudes where the variation of different precipitation intensities with the increase in drought level is relatively complex. (3) As the drought times increase, areas I, II and V, which are located on the coastal and in the valley or basin, are vulnerable to extreme precipitation processes; areas III, IV, VI and VII are located in the inland area, where heavier precipitation is not likely to occur. (4) The local rainfall affected by multiple factors is closely related with drought occurrence. The characteristics between the first rainfall intensity after a drought period and different drought magnitudes (or drought occurrence times) are preliminarily examined in this paper, but its formation mechanism still requires further research.

\section{Introduction}

Under the background of global warming, the occurrence frequency, strength and influence scope of extreme weather/climate events, such as heavy rain, flood and drought, has shown an increasing trend as a result of atmospheric circulation anomaly (Parry et al., 2007). Due to regional climate change, geographical position, terrain conditions and other comprehensive factors, in recent years 
abrupt drought-flood change events, have occurred frequently and widely. For example, the phenomena occurred in the middle and lower reaches of the Yangtze River, AprilJune 2011, and in southwestern China from October 2009 to March 2010. These disasters have caused significant economic losses, creating a new challenge for basin disaster risk management and food security in this changing environment. Precipitation is a key factor in the occurrence of droughts and floods, as the variation of rainfall amount and intensity determines the intensity and influence range of droughts and floods. What changes will occur in precipitation intensity after the occurrence of drought? Will long durations of drought lead to higher rainfall concentration or rainfall intensity? These questions require further research, and studies on these topics will bear great significance in revealing the driving mechanism and evolution tendency of basin flood and drought events.

A large number of scholars have studied the temporal and spatial evolution laws and causes of droughts in many typical basins (or areas), such as the drought evaluation index method based on the observation data of the long series (Cancelliere et al., 2007; Łabędzki, 2007; Palmer, 1965; Dai et al., 2004), numerical simulation method (drought simulation and prediction) of the combination of global (regional) climate models, distributed hydrological model and drought evaluation index, and large-scale drought inversion method based on satellite remote sensing data (Narasimhan and Srinivasan, 2005; Gu et al., 2007; Murthy et al., 2007). In terms of the spatiotemporal evolution law of flood and drought, studies mainly based on long series of observed precipitation data of study areas identified the typical flood and drought events, and analyzed the spatial variation patterns and influences (Parthasarathy et al., 1987). Compared with other countries, studies regarding the patterns of drought and flood were performed in China much later, but the rapid development in such research in China during recent years has produced many meaningful results. In the area of flood and drought, Zhang et al. (2009) studied the dry-wet period change characteristics in the Pearl River basin by adopting the standardized precipitation index (SPI). Zhou et al. (2001) performed numerical research concerning summer drought and flood formation mechanisms in the northeast of China, and indicated that the formation of summer droughts and floods in this region are closely related to the seasonal conversion from winter to summer in East Asia. For research concerning drought patterns in the Huang-Huai-Hai River basin, Zhao et al. (2011) calculated the standardized precipitation index at different timescales using a long series of precipitation data, and also studied the spatiotemporal differences and dynamic patterns of drought for different climatic sub-regions in the Huang-Huai-Hai River basin. Peng et al. (2011) and Feng (2003), as well as other scholars, have used drought analysis methods based on the runs theory to study the respective long data series of drought distribution characteristics of spatiotemporal variability in the Yellow River and Hai River basins. A relatively large amount of research concerning the abrupt drought-flood changes in the Huai River basin, as well as the temporal (season and year) and spatial (basin, two-level district of water resources and region) evolution characteristics of abrupt drought-flood change has been analyzed by adopting floodto-drought change indexes such as the SPI flood-drought index (Cheng et al., 2012), the ten-day precipitation anomaly percentage index (Wang et al., 2009), and the experience precipitation threshold index (Zhang et al., 2008). In summary, in the past many of these studies have focused on the analysis of the spatiotemporal distribution of floods and droughts, while little analysis regarding the rainfall intensity change patterns following a drought period in combination with regional climate characteristics exists.

Due to this fact, the Huang-Huai-Hai River basin is taken as the subject of this paper. By combining the Chinese climate zoning and the basin's digital elevation model (DEM), the basin area is divided into seven sub-regions via cluster analysis of the 171 meteorological stations located in the basin, using the self-organizing map (SOM) neural network method. Based on the results, the spatiotemporal evolution characteristics of the basin are analyzed using the number of consecutive days without precipitation as the drought magnitude index. The first precipitation frequency following a drought period is analyzed with the Pearson-III frequency curve, then the relationship between rainfall intensity and different drought magnitude is shown, as is that of drought frequency change in different years. Finally, the theoretic basis and references for comprehensively coping with extreme weather/climate event risks in the Huang-Huai-Hai River basin are provided.

\section{Description of the study area}

The Huang-Huai-Hai River basin includes the Yellow River basin, Huai River basin and Hai River basin, and is located within the geographic coordinates of $95^{\circ} 53^{\prime}-$ $122^{\circ} 42^{\prime} \mathrm{E}$ and $30^{\circ} 57^{\prime}-42^{\circ} 43^{\prime} \mathrm{N}$. The total area of the basin is $1445000 \mathrm{~km}^{2}$, accounting for approximately $15 \%$ of the total national area, including a plain area of $524000 \mathrm{~km}^{2}$ and mountainous area of $921000 \mathrm{~km}^{2}$. The cultivated land, population and GDP (gross domestic product) in this basin accounted for approximately 35,34 and $38 \%$ of the national totals in 2008 , showing that the basin plays an important role in China's economic and social development. The general situations of the study area are shown in Table 1. The Huang-Huai-Hai River basin mainly consists of plateaus, mountains, basins, and plains, with a "three-level ladder" terrain feature, being higher in the west and gradually lower in the east. Among these three steps, the first and highest is the Tibetan Plateau, which has an average altitude of greater than $4000 \mathrm{~m}$. The second step consists of plateaus, mountains and basins located in the west of the 
Yanshan-Taihang Mountains, at an average altitude ranging from 1000 to $2000 \mathrm{~m}$. The third step ranges from the east of the Yanshan-Taihang Mountains to the broad coastal plains, at an average elevation of more than $500 \mathrm{~m}$. The geographical location and topography distribution of the Huang-Huai-Hai River basin are shown in Fig. 1.

The climate of the Huang-Huai-Hai River basin is quite complex, consisting mainly of temperate continental, temperate monsoon, plateau mountain and subtropical monsoon climates. The details of the different climate regions are as follows: (1) the temperate continental climate is controlled by polar cold air masses, resulting in extreme continental climate and low annual rainfall. (2) The temperate monsoon climate is characterized by cold and dry winters, caused by north winds from high inland latitudes, and hot and rainy summers, influenced by marine polar air and the degeneration of tropical marine air. (3) The plateau mountain climate is affected by high altitudes and mountain terrain, the vertical change of climate is significant, and precipitation and precipitation days vary with the mountain altitude changes. (4) The subtropical monsoon climate area is a strip controlled by alternating tropical marine and polar continental air competing with one another. The monsoon is formed by seasonal alternations under the influence of temperature differences between sea and land in summer, and wind from Siberia in winter.

The Huang-Huai-Hai River basin is one of China's most important political, economic and cultural centers, and is also one of the regions that experiences the most frequent and severe occurrences of flood and drought disasters. The flood and drought characteristics of the various basins show clear differences. Observations have shown that more precipitation occurred in the Yellow River basin in the 1960s and 1980s, and temperatures increased significantly and precipitation decreased in the 1970s and 1990s; at present the basin experiences less rainfall than before, and the drought situation has become more and more severe (Shao et al., 2006). The Huai River basin is located in the climate transition zone between the north and south, and flood-to-drought alternations between south floods and north droughts occur frequently, due to the common effects of weather systems at low and mid-high latitudes. Abrupt drought-flood change events have occurred frequently since the 1960s. A total of 13 of these events occurred from 1960 to 2009, at an average of once every four years, and since 2000 the occurrence frequency has increased significantly (Cheng et al., 2012; Wang et al., 2009; Zhang et al., 2008; Tang et al., 2007). The Hai River basin is one of China's frequent drought occurrence regions, and is known as the "nine drought years out of ten" region. Since the 1980s, precipitation has gradually reduced in this region year by year. Since 1997, the Hai River basin encountered drought in five consecutive years, affecting the entire basin. The regional climate model prediction results show that the Huang-Huai-Hai plain will experience its driest period from 2011 to 2040, during which time the

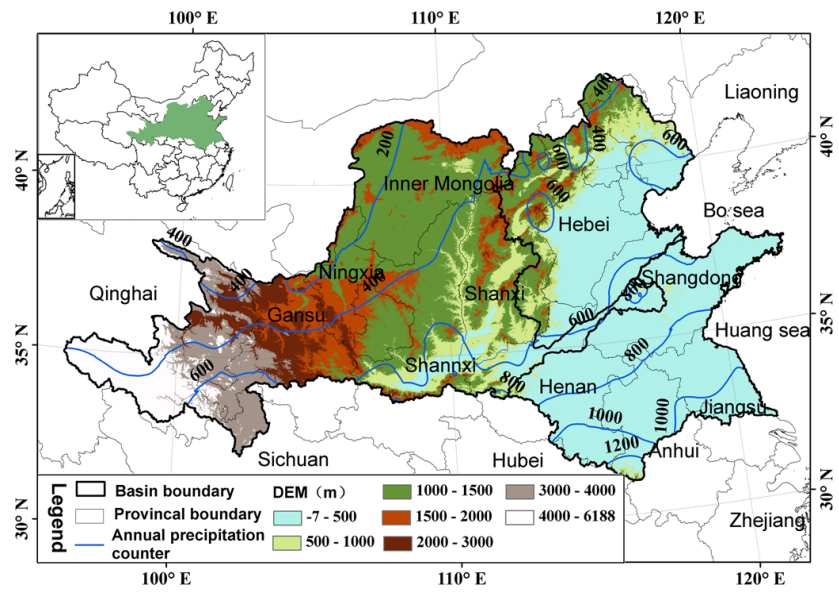

Fig. 1. Location and topography of the Huang-Huai-Hai River basin.

frequency and duration of extreme droughts will reach their maximum, as shown in the SRES (Special Report on Emission Scenarios) A2 scenario (Marengo et al., 2009).

\section{Materials and methods}

\subsection{Data sources}

In this paper, the daily precipitation data for 171 meteorological stations in and around the Huang-Huai-Hai River basin for the years 1961 to 2001 provided by China National Climate Center are selected, and the number of consecutive days without precipitation for both interannual and interdecadal periods are determined.

\subsection{Clustering methods of SOM and division}

Due to the geographical positioning of the meteorological stations, the altitude and precipitation features differ throughout the basin. Meteorological stations within the basin with similar features require clustering analysis and partitioning, thus the intensity changes during alternate dry-wet cycles vary among the sub-regions. In this paper, the longitude and latitude of each meteorological station (the $x$ and $y$ values in the geodetic coordinate system), as well as their respective altitudes and annual mean precipitations, were selected during the cluster analysis via the SOM neural network algorithm (Kohonen, 2001). Compared with other classification methods, SOM is a network capable of self organization and self learning; its other advantages include that it realizes realtime learning, possesses network stability, does not require external evaluation functions, recognizes the most significant characteristics of the vector space, has good anti-noise ability, and so on (Yang et al., 2006). 
Table 1. General characteristics of the study area.

\begin{tabular}{|c|c|c|c|c|}
\hline Basin & $\begin{array}{r}\text { Area } \\
\left(\mathrm{km}^{2}\right)\end{array}$ & Provinces & $\begin{array}{l}\text { Annual mean } \\
\text { precipitation } \\
(\mathrm{mm})\end{array}$ & $\begin{array}{l}\text { Annual mean } \\
\text { temperatures } \\
\left({ }^{\circ}\right)\end{array}$ \\
\hline Yellow River basin & 795000 & $\begin{array}{l}\text { Qinghai, Sichuan, Gansu, } \\
\text { Ningxia, Inner Mongolia, } \\
\text { Shaanxi, Shanxi, Henan, } \\
\text { Shandong }\end{array}$ & 446 & $5.7-14.2$ \\
\hline Huai River basin & 330000 & $\begin{array}{l}\text { Henan, Anhui, Jiangsu, } \\
\text { Shandong }\end{array}$ & 888 & $11.0-16.0$ \\
\hline Hai River basin & 320000 & $\begin{array}{l}\text { Hebei, Shanxi, Henan, } \\
\text { Shandong, Inner Mongolia, } \\
\text { Liaoning }\end{array}$ & 883 & $1.5-14.0$ \\
\hline
\end{tabular}

In this paper, we programmed the designed steps by the neural network toolbox in Matlab 7.1. The main procedures of SOM clustering method are as follows:

1. Normalization of input data.

$$
y_{i}=\frac{y-y_{\min }}{y_{\max }-y_{\min }}
$$

where $y_{i}$ is the standardization value of a variable, $y$ is a variable, $y_{\max }$ is the maximum value of a variable series, and $y_{\min }$ is the minimum value of a variable series.

2. Inputting vectors.

$$
P=\left[\begin{array}{cccc}
0.7877 & 0 & 0.0276 & 1 \\
0.7584 & 0.0290 & 0.0129 & 0.8616 \\
\ldots & & & \\
0.7049 & 1 & 0.2817 & 0.1854
\end{array}\right]
$$

3. Construction of the SOM model.

net $=$ newsom $(\min \max (P),[64])$;

net $\cdot$ trainParam $\cdot$ epochs $=a$.

The network structure of $6 \times 4$ is applied in the output layer, and the epochs of training $a$ are 5, 10 and 100 respectively. The larger the training step is, the more accurate the classification is. We only preliminarily cluster to the 171 stations, and the result is chosen when the training step is 5 .

4. Training and simulating.

net $=$ train $($ net, $P)$;

$y=\operatorname{sim}($ net, $P)$.

Through calculating the minus distances between the weight vector and the input vectors we gained the weight inputs, which are also the inputs of the characteristic mapping layer. Then, the inputs of the characteristic mapping layer find the winning neuron by competition. The results of clustering analysis are listed in the Table 2 .
5. Outputs of the network.

$$
y c=\operatorname{vec} 2 \operatorname{ind}(y) .
$$

In view of the clustering results of the SOM method, 171 stations are divided into 23 sorts, and the sort with no more than 2 stations are merged into the nearby sorts by considering the stations' spatial location, then all the stations are divided into 14 sorts. The clustering results of the stations' spatial distributions are shown in Fig. 2 (in which the same digital label represents the same class).

Combining the climate divisions of China and basin DEM, the basin is divided into seven sub-regions (Fig. 3) via cluster analysis using the SOM neural network method. The basic information of subarea presents in Table 3. In area I there are 25 representative meteorological stations, accounting for $14.6 \%$ of the total number of stations, which are mainly distributed in the area surrounding Bo Sea and the Shandong Peninsula. Area II has 14 stations, accounting for $8.2 \%$, which are mainly distributed in the Huai River downstream. Area III has 31 stations, accounting for $18.1 \%$, which are mainly distributed throughout the alternate drought and flood prone areas, such as the upper and middle reaches of the Huai River, as well as the Daqing River, Ziya River and Zhangwei River plains in the Hai River basin. Area IV has 30 stations, accounting for $17.5 \%$, which are mainly distributed on the Hetao Plain in Ningxia-Inner Mongolia and Inner Mongolia Plateau. Area V has 23 stations, accounting for $13.5 \%$, which are mainly distributed in the Fen-Wei Valley basin in the Shanxi and Shaanxi provinces, as well as on the Loess Plateau. Area VI has 22 representative meteorological stations, accounting for $12.9 \%$, which are mainly located in the high mountains and hilly regions at altitudes of 1500 $3000 \mathrm{~m}$. And in area VII there are 26 stations, accounting for $15.2 \%$, which are mainly located on the Tibetan Plateau in the Yellow River basin, at altitudes above $3000 \mathrm{~m}$. 
Table 2. The results of clustering analysis.

\begin{tabular}{llllllllll}
\hline Sort & $\begin{array}{l}\text { Station } \\
\text { numbers }\end{array}$ & Sort & $\begin{array}{l}\text { Station } \\
\text { numbers }\end{array}$ & Sort & $\begin{array}{l}\text { Station } \\
\text { numbers }\end{array}$ & Sort & $\begin{array}{l}\text { Station } \\
\text { numbers }\end{array}$ & Sort & $\begin{array}{l}\text { Station } \\
\text { numbers }\end{array}$ \\
\hline 1 & 22 & 6 & 1 & 11 & 3 & 16 & 2 & 21 & 2 \\
2 & 2 & 7 & 2 & 12 & 7 & 17 & 24 & 22 & 6 \\
3 & 10 & 8 & 23 & 13 & 1 & 18 & 3 & 23 & 20 \\
4 & 8 & 9 & 1 & 14 & 3 & 19 & 4 & & \\
5 & 2 & 10 & 1 & 15 & 15 & 20 & 9 & & \\
\hline
\end{tabular}

Table 3. Basic information of basin subareas.

\begin{tabular}{llcr}
\hline Subarea & Climate type & $\begin{array}{r}\text { Meteorological } \\
\text { station number }\end{array}$ & $\begin{array}{r}\text { Ratio } \\
(\%)\end{array}$ \\
\hline I & temperate monsoon climate & 25 & 14.6 \\
II & & 14 & 8.2 \\
III & temperate monsoon climate, subtropical monsoon climate & 31 & 18.1 \\
IV & temperate continental climate & 30 & 17.5 \\
V & temperate monsoon climate & 23 & 13.5 \\
VI & & 22 & 12.9 \\
VII & plateau mountain climate & 26 & 15.2 \\
\hline
\end{tabular}

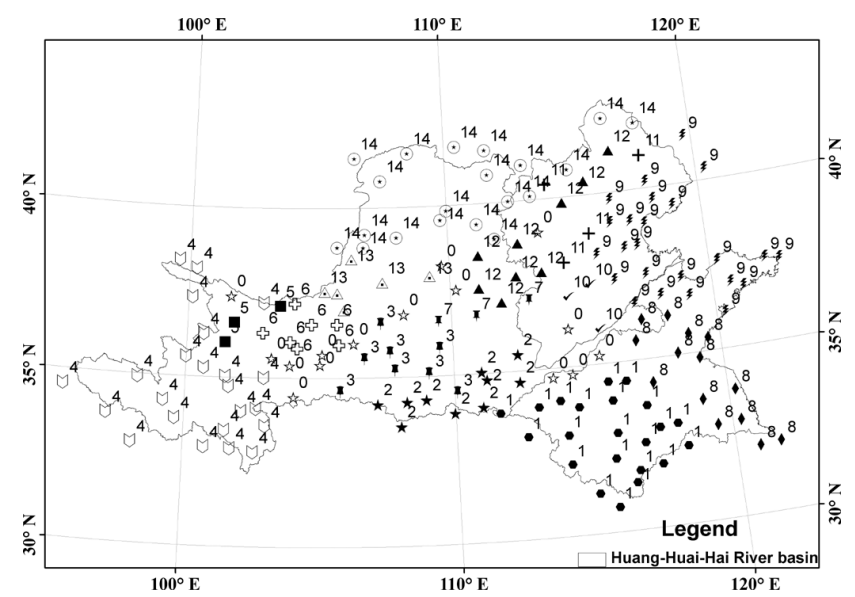

Fig. 2. Spatial distribution of SOM clustering results in various subareas.

\subsection{Drought magnitude standards}

At present, there exist many evaluation indexes of drought magnitudes based on different drought types, such as precipitation anomaly percentage, standardized precipitation index (SPI), relative soil moisture, Palmer drought severity index (PDSI), etc. In this paper, in order to compare the availability of data, scope and content of the index, as well as the difficulty of calculation, the number of consecutive days without precipitation is used as the drought indicator to determine the drought magnitude. Consecutive rainless days refer to the number of consecutive days without precipitation. Based on the Standard of Classification for Drought Severity
Table 4. Consecutive rainless days and drought magnitude standards.

\begin{tabular}{|c|c|c|c|c|}
\hline \multirow[b]{2}{*}{ Season } & \multicolumn{4}{|c|}{$\begin{array}{l}\text { The number of consecutive rainless days } \\
\text { in different drought magnitude }\end{array}$} \\
\hline & $\begin{array}{l}\text { Light } \\
\text { drought } \\
\text { (d) }\end{array}$ & $\begin{array}{l}\text { Moderate } \\
\text { drought } \\
\text { (d) }\end{array}$ & $\begin{array}{l}\text { Severe } \\
\text { drought } \\
\text { (d) }\end{array}$ & $\begin{array}{l}\text { Extraordinary } \\
\text { drought } \\
\text { (d) }\end{array}$ \\
\hline Spring (Mar-May) & $15-30$ & $31-50$ & $51-75$ & $>75$ \\
\hline Summer (Jun-Aug) & $10-20$ & $31-50$ & $>50$ & \\
\hline Autumn (Sep-Nov) & $15-30$ & $31-50$ & $51-75$ & $>75$ \\
\hline Winter (Dec-Feb) & $20-30$ & $31-60$ & $61-80$ & $>80$ \\
\hline
\end{tabular}

(SL424-2008) released by the Ministry of Water Resources of the People's Republic of China in 2008, the drought evaluation criteria of consecutive rainless days are shown in Table 4 . According to the criteria, days with precipitation less than $3 \mathrm{~mm}$ in spring (March-May) and autumn (SeptemberNovember), and less than $5 \mathrm{~mm}$ in summer (June-August), are considered to be rainless days. If the consecutive rainless days span more than one season, the drought magnitude will be determined based on the season with the majority of the consecutive rainless days; if the consecutive rainless days span two or three consecutive seasons, it will be considered as an extraordinary drought.

\subsection{Analysis of precipitation intensity and frequency}

In this paper, first precipitation after a drought period is used as the precipitation intensity, in order to obtain the amount of the first precipitation after a drought period in each subarea of the basin, then the temporal and spatial 


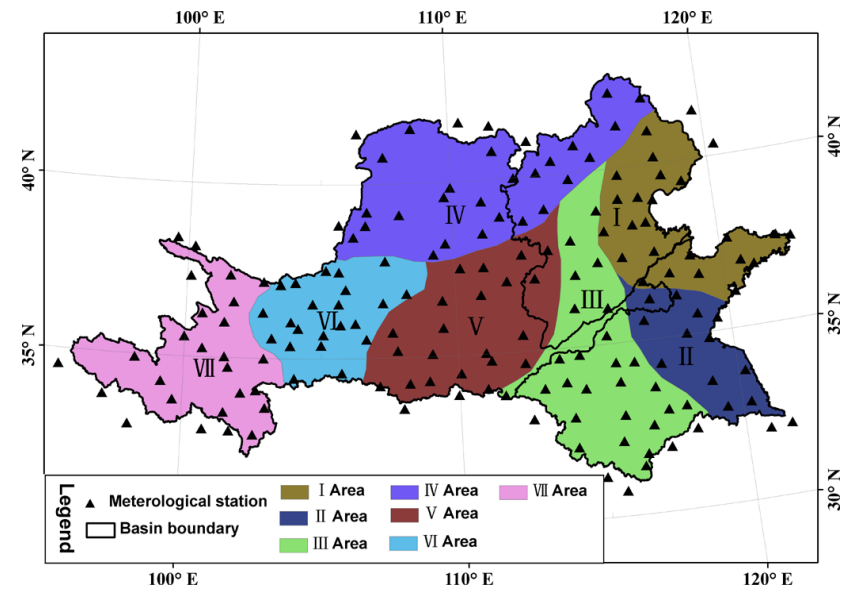

Fig. 3. Subareas of the Huang-Huai-Hai River basin.

variations are analyzed. According to the precipitation magnitude standards (Xiao et al., 2009) (Table 5), light rain refers to rainfall with $24 \mathrm{~h}$ of accumulated precipitation of less than $10 \mathrm{~mm}$; moderate rain $10.1-25.0 \mathrm{~mm}$; heavy rain $25.1-$ $50.0 \mathrm{~mm}$; rainstorm $50.1-100.0 \mathrm{~mm}$; heavy rainstorm $100.1-$ 250.0; and extraordinary rainstorm more than $250.0 \mathrm{~mm}$.

Precipitation distribution is a type of skewness distribution, thus the gamma distribution probability may be used to describe the precipitation probability and calculate cumulative frequency distribution (Zhai and Feng, 2011). The Pearson-III asymmetric unimodal curve is used for the analysis of the probability density function, which is as follows:

$f(x)=\frac{\beta^{\alpha}}{\Gamma(\alpha)}\left(x-a_{0}\right)^{\alpha-1} e^{-\beta\left(x-\alpha_{0}\right)}$,

where $\Gamma(\alpha)$ is the gamma function of $\alpha$, and $\alpha, \beta, a_{0}$ are the parameters of Pearson-III in terms of shape, dimension and position, respectively $\alpha>0, \beta>0$. In this paper, the first precipitations after drought periods in different magnitudes are determined, then Pearson-III is applied to analyze the frequency of the first precipitations. On the basis of the previous study, this paper analyzes the change characteristics of the frequency of first precipitations after drought periods, and reveals the relationship between the different levels of drought and rainfall intensity.

\section{Results and discussion}

\subsection{Spatiotemporal change trends with different drought magnitudes}

In this paper, the amount of consecutive days without precipitation is used as the drought evaluation index to determine the drought occurrence times for different years and with different magnitudes, then the change trends are analyzed. The results are shown in Fig. 4.
Table 5. Precipitation magnitude standards.

\begin{tabular}{ll}
\hline precipitation magnitude & $24 \mathrm{~h}$ precipitation $/\left(\mathrm{mm} \mathrm{d}^{-1}\right)$ \\
\hline Light rain & $0.0-10.0$ \\
Moderate rain & $10.1-25.0$ \\
Heavy rain & $25.1-50.0$ \\
Rainstorm & $50.1-100.0$ \\
Heavy rainstorm & $100.1-250.0$ \\
Extraordinary rainstorm & $>250.0$ \\
\hline
\end{tabular}

Figure 4a shows the statistics of light drought occurrence times in each subarea for the years 1961-2011. In terms of time, the interdecadal changes of light drought occurrence times are not apparent in any of the subareas, showing an overall upward fluctuation trend, except for areas II and VI, which show no significant reducing trends. Among the areas, drought times increased relatively rapidly in areas $\mathrm{V}$ and I compared with the 1960s, increasing by 11.67 and $8.46 \%$, respectively. These are followed by areas VII, IV and III, the respective drought times increase by rates of 4.47, 3.82 and $1.59 \%$. Finally, the drought times in areas VI and II show slight reduction, with respective increase rates of -3.11 and $-0.09 \%$. From the perspective of space, the light drought occurrence times of areas II, III and V are comparatively higher, respectively occurring on average 57,57 and 54 times every $10 \mathrm{yr}$; the drought occurrence times in area IV and VII are significantly lower, at 36 and 37 times every $10 \mathrm{yr}$.

Figure $4 \mathrm{~b}$ shows the statistics of the moderate drought occurrence times in each subarea for the years 1961-2011. In terms of time, the interdecadal change of moderate drought occurrence times in each subarea is not apparent, showing an overall upward fluctuation trend, except for area I, which shows a clear reducing trend. Among the areas, the number of drought times increases relatively rapidly in areas $\mathrm{V}$ and IV compared with the 1960s, increasing 23.93 and $22.59 \%$, respectively. These are followed by areas VI and III, with respective drought times increase rates of 12.5 and $7.86 \%$. In areas II and VII, the respective drought times' increase rates are only 1.16 and $0.80 \%$, showing no significant increase. The drought times in area I show a significant reduction, with an increase rate of $-14.82 \%$. In terms of space, the moderate drought occurrence times in areas II and III is comparatively higher, each occurring on average 19 times every $10 \mathrm{yr}$; these are followed by areas I and V, both at 15 times every $10 \mathrm{yr}$; 11 times in areas IV and VI; and only 6 times in area VII, which is considered relatively low.

Figure $4 \mathrm{c}$ shows the statistics of severe drought occurrence times in each subarea for the years 1961-2011. In terms of time, the interdecadal change of severe drought occurrence times in each subarea is not clear, showing an overall upward trend, except for area III, which shows no clear reducing trend. Among the areas, drought times increased relatively rapidly in areas VI and II compared with the 1960s, 


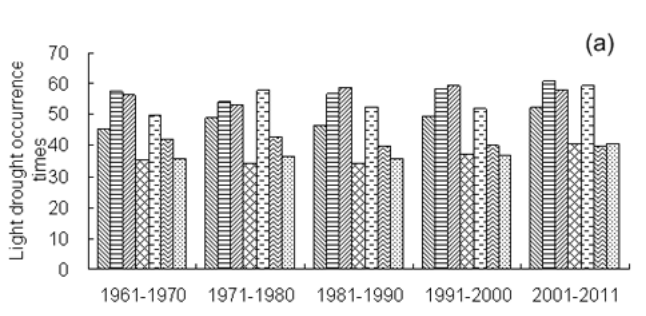

Year

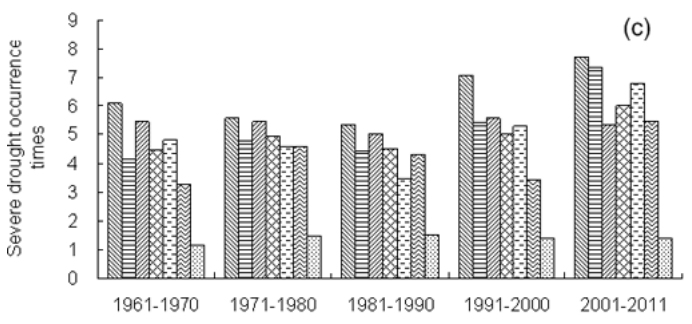

Year

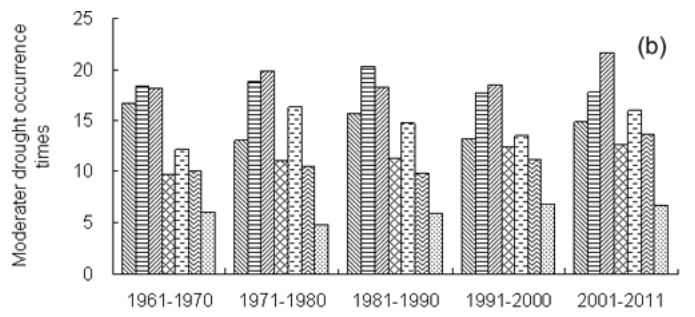

Year

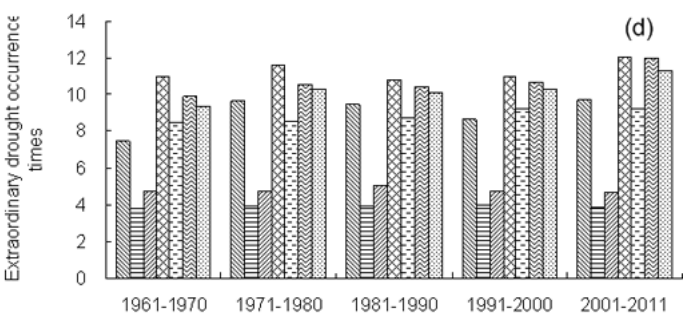

Year

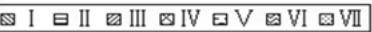

Fig. 4. Interdecadal changes of light (a), moderate (b), severe (c) and extraordinary (d) droughts; occurrence times of the seven subareas. Note: I - areas surrounding Bo Sea and the Shandong Peninsula; II - Huai River downstream; III - piedmont plains of upper and middle reaches of the Huai and Hai River basins; IV - Hetao Plains and Inner Mongolia Plateau; V - Loess Plateau and Fen-Wei Valley basin; VI mountains and hills at altitudes of 1500-3000 m; VII - Tibetan Plateau at altitudes above $3000 \mathrm{~m}$.

increasing by 35.76 and $32.76 \%$, respectively. These are followed by area VII and IV, their respective drought times' increase rates are 24.17 and $14.55 \%$. Those of areas V and I are 4.5 and $5.59 \%$, respectively, showing no significant increase. That in area III shows a slight reduction, at $-1.92 \%$. From the perspective of space, the severe drought occurrence times in areas I-V are relatively high, occurring on average about 5 times every $10 \mathrm{yr}$, while that in area VII is relatively low, occurring on average only once every $10 \mathrm{yr}$.

Figure $4 \mathrm{~d}$ shows the statistics of extraordinary drought occurrence times in each subarea for the years 1961-2011. In terms of time, the interdecadal changes of extraordinary drought occurrence times are not significant in any of the subareas, showing an overall upward trend. Among the areas, drought times increased relatively rapidly in areas I, VII and VI compared with the 1960s, increasing by $25.94,12.76$ and $10.94 \%$, respectively. The drought times' increase rates of areas II-V are all about $5 \%$, showing no clear increasing trend. In terms of space, the extraordinary drought occurrence times in areas I, and IV-VII are relatively high, at an average of about 10 times every $10 \mathrm{yr}$; those of areas II and III are relatively low, at an average of 5 times every $10 \mathrm{yr}$.

Above all, the interdecadal changes of occurrence times with different drought magnitudes are not significant, but the spatial differences among them are quite large. Drought occurrence times with different magnitudes are relatively higher in areas I-V, among which severe drought and extraordinary drought are significantly high in areas I, VI and $\mathrm{V}$, much of which is concentrated on the North China Plain, Hetao Plains in Ningxia-Inner Mongolia, the Inner Mongolia and Loess plateaus, and in the Fen-Wei Valley basin. This is one of the China's most severe drought regions with uneven distribution of rainfall within the year and intense evaporation, which is mainly affected by temperate monsoon and temperate continental climates. Areas II and III are mainly located in the Huai River basin, where the occurrence times of light and moderate droughts are relatively high. The Huai River basin is situated in China's humid and semi-arid climate transition zone, where monsoon climate is extremely significant. Owing to this area's unique geographical location, the weather here is complicated under the impact of weather systems at low and high latitudes. Furthermore, droughts occur frequently in this region due to the large annual and interannual variabilities of precipitation and uneven spatial and temporal distribution.

\subsection{Relations among different magnitudes of drought and precipitation intensity change}

Pearson-III is used to analyze the frequency of first precipitation after drought with different magnitudes in each subarea of the Huang-Huai-Hai River basin. Due to limited space, this paper only takes area I as an example. The best fitting curve is selected and the frequency curve of first precipitation after drought with different magnitudes is drawn. Then, the respective frequencies of moderate rain, heavy rain, rainstorm and heavy rainstorm with different magnitudes of drought are determined. Due to the fact that the probability of light rain is $100 \%$ and that of extraordinary rainstorm is about 0 , neither are considered. 

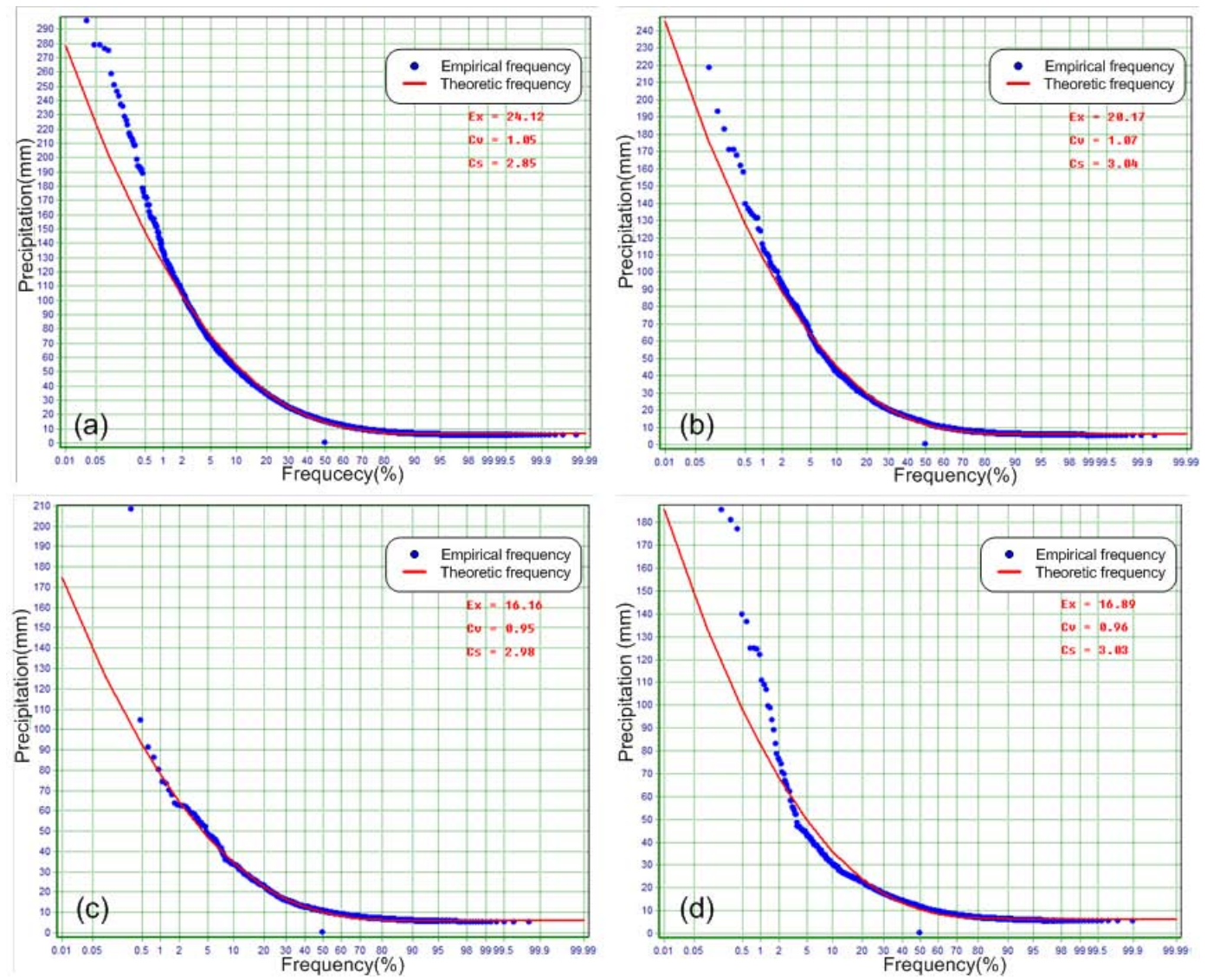

Fig. 5. Pearson-III curves of first precipitation after drought of different magnitudes in area I; (a) light drought; (b) moderate drought; (c) severe drought; (d) extraordinary drought.

Figure 5a shows a Pearson-III curve of light drought. From the figure it may be concluded that the frequency above moderate rain is $64.65 \%$, and that above heavy rain is $30.45 \%$, thus the frequency of moderate rain is $34.2 \%$ (moderate rain frequency $=$ moderate rain above frequency - heavy rain above frequency). Based on this analogy, the probability of heavy rain is $18.70 \%$, that of rainstorm is $9.55 \%$, that of heavy rainstorm is $2.18 \%$, and that of extraordinary rainstorm is $0.02 \%$. From Fig. $5 \mathrm{~b}$, the moderate drought Pearson-III curve, it may be seen that the respective probabilities of moderate rain, heavy rain, rainstorm, heavy rainstorm and extraordinary rainstorm are 31.97, 15.76, 7.04, 1.31 and $0.01 \%$. From Fig. 5c, the severe drought PearsonIII curve, it may be seen that the respective probabilities of moderate rain, heavy rain, rainstorm, heavy rainstorm and extraordinary rainstorm are 33.18, 13.06, 3.91, 0.34 and $0 \%$. From Fig. 5d, the extraordinary drought Pearson-III curve, it may be seen that that the respective probabilities of moderate rain, heavy rain, rainstorm, heavy rainstorm and extraordinary rainstorm are $33.71,13.58,4.39,0.45$ and $0 \%$. The precipitation frequencies after drought with different magnitudes in the other subareas for the years 1961-2011 are shown in Table 6.
From Table 6 it may be concluded that in area I, for the drought magnitude from light to moderate and moderate to extraordinary, moderate rain occurrence frequency first reduces then increases, and for that from light to severe and severe to extraordinary, the probability from heavy rain to extraordinary rainstorm first reduces then increases significantly. In area II, for the drought magnitude from light to moderate and moderate to extraordinary, moderate rain occurrence frequency first reduces and then increases, and for that from light to severe, the probability from heavy rain to extraordinary rainstorm reduces. When droughts continue to develop and form extraordinary droughts, the different intensity precipitations show clear increasing trends. In area III, for the drought from light to moderate and from moderate to extraordinary, moderate rain occurrence first reduces then increases, while that for from light to extraordinary, the probability from heavy rain to extraordinary rainstorm gradually reduces. In area IV, for the drought magnitude from light to severe, the probability from moderate rain to heavy rainstorm reduces; when droughts continue to develop and form extraordinary droughts, the probability of moderate rain to heavy rainstorm increases. 
Table 6. Different precipitation intensities after drought magnitude in each subarea.

\begin{tabular}{|c|c|c|c|c|c|c|}
\hline Subarea & Magnitude & $\begin{array}{r}\text { Moderate rain } \\
(\%)\end{array}$ & $\begin{array}{r}\text { Heavy rain } \\
(\%)\end{array}$ & $\begin{array}{r}\text { Rainstorm } \\
(\%)\end{array}$ & $\begin{array}{r}\text { Heavy rainstorm } \\
(\%)\end{array}$ & $\begin{array}{r}\text { Extraordinary } \\
\text { rainstorm } \\
(\%)\end{array}$ \\
\hline \multirow[t]{4}{*}{ I } & Light drought & 34.20 & 18.70 & 9.55 & 2.18 & 0.02 \\
\hline & Moderate drought & 31.97 & 15.76 & 7.04 & 1.31 & 0.01 \\
\hline & Severe drought & 33.18 & 13.06 & 3.91 & 0.34 & 0 \\
\hline & Extraordinary drought & 33.71 & 13.58 & 4.39 & 0.45 & 0 \\
\hline \multirow[t]{4}{*}{ II } & Light drought & 33.60 & 19.21 & 10.53 & 2.77 & 0.04 \\
\hline & Moderate drought & 30.87 & 16.24 & 8.94 & 2.61 & 0.05 \\
\hline & Severe drought & 32.18 & 15.73 & 7.28 & 1.48 & 0.01 \\
\hline & Extraordinary drought & 31.02 & 17.20 & 9.97 & 3.13 & 0.08 \\
\hline \multirow[t]{4}{*}{ III } & Light drought & 32.76 & 18.92 & 11.09 & 3.44 & 0.08 \\
\hline & Moderate drought & 32.41 & 17.11 & 8.61 & 2.01 & 0.02 \\
\hline & Severe drought & 32.91 & 17.88 & 8.72 & 1.82 & 0.02 \\
\hline & Extraordinary drought & 35.48 & 17.59 & 7.09 & 1.02 & 0 \\
\hline \multirow[t]{4}{*}{ IV } & Light drought & 37.39 & 14.52 & 3.65 & 0.21 & 0 \\
\hline & Moderate drought & 35.08 & 12.19 & 2.72 & 0.14 & 0 \\
\hline & Severe drought & 27.82 & 8.33 & 1.73 & 0.08 & 0 \\
\hline & Extraordinary drought & 30.70 & 10.12 & 2.39 & 0.14 & 0 \\
\hline \multirow[t]{4}{*}{$\mathrm{V}$} & Light drought & 36.91 & 18.6 & 7.07 & 0.86 & 0.01 \\
\hline & Moderate drought & 33.25 & 13.69 & 4.21 & 0.38 & 0 \\
\hline & Severe drought & 30.11 & 12.34 & 3.84 & 0.37 & 0 \\
\hline & Extraordinary drought & 33.32 & 12.49 & 3.49 & 0.27 & 0 \\
\hline \multirow[t]{4}{*}{ VI } & Light drought & 38.45 & 13.70 & 2.89 & 0.12 & 0 \\
\hline & Moderate drought & 33.40 & 10.61 & 2.08 & 0.08 & 0 \\
\hline & Severe drought & 37.43 & 9.75 & 1.12 & 0.02 & 0 \\
\hline & Extraordinary drought & 35.93 & 9.37 & 1.25 & 0.02 & 0 \\
\hline \multirow[t]{4}{*}{ VII } & Light drought & 36.42 & 10.34 & 1.57 & 0.04 & 0 \\
\hline & Moderate drought & 30.67 & 6.46 & 0.66 & 0.01 & 0 \\
\hline & Severe drought & 25.38 & 3.88 & 0.25 & 0 & 0 \\
\hline & Extraordinary drought & 30.38 & 8.8 & 1.61 & 0.06 & 0 \\
\hline
\end{tabular}

In area $\mathrm{V}$, for the drought magnitude from light to severe and from severe to extraordinary, the probability from moderate rain to heavy rain first reduces and then increases, while for that from light to extraordinary, the probability from rainstorm to heavy rainstorm reduces. In area VI, with the increase of drought magnitude, the probability of each precipitation intensity change becomes complicated. In area VII, for the drought magnitude from light to severe and from severe to extraordinary, the probability from moderate rain to heavy rainstorm first reduces and then increases.

In summary, with the increase in drought magnitude, the probability of extraordinary rainstorm, in the Huang-HuaiHai River basin becomes lower. However, the changes of precipitation occurrence frequency differ among the various subareas and intensities. In areas I and II (the areas surrounding Bo Sea, the Shandong Peninsula and the Huai River downstream), with the increase of drought magnitude, the probabilities of different precipitation intensities first show decreasing trends. When droughts continue to develop and form extraordinary droughts, the probabilities of different precipitation intensities increase. In area III (the upper and middle reaches of the Huai River and Hai River basin piedmont plains), with the increase of drought magnitude, the probabilities of different precipitation intensities show decreasing trends. In areas IV and V (Hetao Plains in NingxiaInner Mongolia, Inner Mongolia and Loess plateaus and Fen-Wei Valley basin), with the increase of drought magnitude, the probabilities of different precipitation intensities show decreasing trends. In areas IV and V (the mountain hills and Tibetan Plateau at altitudes above $3000 \mathrm{~m}$ ), the probabilities of each precipitation intensity change are complicated. Due to the complex topography of the plateau mountain climate region, the precipitation intensity shows significantly uncertainty by the impact of mountain altitude, slope, valley basin, etc. 
Table 7. Drought occurrence times and precipitation intensities in each subarea.

\begin{tabular}{|c|c|c|c|c|c|c|c|}
\hline Subarea & Period & Drought times & $\begin{array}{r}\text { Moderate rain } \\
(\%)\end{array}$ & $\begin{array}{r}\text { Heavy rain } \\
(\%)\end{array}$ & $\begin{array}{r}\text { Rainstorm } \\
(\%)\end{array}$ & $\begin{array}{r}\text { Heavy rainstorm } \\
(\%)\end{array}$ & $\begin{array}{r}\text { Extraordinary } \\
\text { rainstorm } \\
(\%)\end{array}$ \\
\hline \multirow[t]{5}{*}{ I } & $1961-1970$ & 76 & 35.4 & 17.42 & 6.95 & 0.99 & 0 \\
\hline & 1971-1980 & 77 & 31.63 & 16.53 & 8.77 & 2.34 & 0.04 \\
\hline & 1981-1990 & 77 & 31.68 & 17.53 & 8.43 & 1.92 & 0.02 \\
\hline & 1991-2000 & 78 & 32.5 & 17.28 & 8.79 & 2.08 & 0.02 \\
\hline & 2001-2011 & 85 & 34.94 & 18.11 & 7.85 & 1.29 & 0.01 \\
\hline \multirow[t]{5}{*}{ II } & $1961-1970$ & 84 & 32.24 & 17.64 & 9.31 & 2.36 & 0.03 \\
\hline & 1971-1980 & 82 & 34.79 & 18.26 & 8.97 & 1.95 & 0.02 \\
\hline & 1981-1990 & 85 & 33.06 & 19.18 & 11.21 & 3.43 & 0.07 \\
\hline & 1991-2000 & 85 & 31.72 & 17.83 & 10.35 & 3.22 & 0.07 \\
\hline & 2001-2011 & 90 & 34.18 & 19.14 & 9.73 & 2.17 & 0.02 \\
\hline \multirow[t]{5}{*}{ III } & $1961-1970$ & 85 & 32.14 & 17.7 & 10.03 & 3 & 0.06 \\
\hline & 1971-1980 & 83 & 32.55 & 17.97 & 9.47 & 2.36 & 0.03 \\
\hline & 1981-1990 & 87 & 33.77 & 20.02 & 10.64 & 2.52 & 0.03 \\
\hline & 1991-2000 & 88 & 32.16 & 18.34 & 11.04 & 3.68 & 0.1 \\
\hline & 2001-2011 & 89 & 32.77 & 18.52 & 10.11 & 2.69 & 0.04 \\
\hline \multirow[t]{5}{*}{ IV } & $1961-1970$ & 60 & 35.42 & 12.74 & 3.1 & 0.18 & 0 \\
\hline & 1971-1980 & 62 & 34.19 & 12.79 & 3.34 & 0.22 & 0 \\
\hline & 1981-1990 & 61 & 35.61 & 12.6 & 2.91 & 0.15 & 0 \\
\hline & 1991-2000 & 66 & 35.14 & 12.96 & 3.21 & 0.19 & 0 \\
\hline & 2001-2011 & 71 & 37.19 & 13.86 & 3.23 & 0.16 & 0 \\
\hline \multirow[t]{5}{*}{$\mathrm{V}$} & 1961-1970 & 75 & 36.84 & 15.93 & 4.84 & 0.41 & 0 \\
\hline & 1971-1980 & 87 & 35.24 & 16.5 & 5.86 & 0.66 & 0 \\
\hline & 1981-1990 & 79 & 36.75 & 17.74 & 6.18 & 0.64 & 0 \\
\hline & 1991-2000 & 80 & 35.78 & 18.12 & 6.97 & 0.88 & 0 \\
\hline & 2001-2011 & 91 & 33.91 & 16.12 & 6.25 & 0.85 & 0 \\
\hline \multirow[t]{5}{*}{ VI } & 1961-1970 & 65 & 35.23 & 12.7 & 3 & 0.16 & 0 \\
\hline & 1971-1980 & 68 & 35.94 & 11.08 & 1.96 & 0.06 & 0 \\
\hline & 1981-1990 & 65 & 39.26 & 12.04 & 1.92 & 0.05 & 0 \\
\hline & 1991-2000 & 66 & 38.42 & 12.73 & 2.52 & 0.09 & 0 \\
\hline & 2001-2011 & 71 & 38.03 & 13.4 & 2.69 & 0.1 & 0 \\
\hline \multirow[t]{5}{*}{ VII } & 1961-1970 & 52 & 36.12 & 8.8 & 1.03 & 0.02 & 0 \\
\hline & 1971-1980 & 53 & 32.32 & 10.17 & 2.05 & 0.09 & 0 \\
\hline & 1981-1990 & 53 & 34.33 & 8.73 & 1.11 & 0.02 & 0 \\
\hline & 1991-2000 & 55 & 34.91 & 9.43 & 1.35 & 0.03 & 0 \\
\hline & 2001-2011 & 60 & 35.18 & 9.59 & 1.4 & 0.03 & 0 \\
\hline
\end{tabular}

\subsection{Relationship between drought occurrence times and precipitation intensity}

Table 7 shows the drought occurrence times and precipitation intensity of each subarea for the years 1961-2011. From the table we may draw the following conclusions: the drought occurrence times in area I grows by $4.83 \%$ compared with the 1960s. While moderate rain and heavy rain frequency show decreasing trends with the increase of drought times (with the average increase rates of -7.66 and $-0.33 \%$ ), the other types show increasing trends, among which the average increase rates of rainstorm and heavy rainstorm frequency are 21.73 and $92.68 \%$, respectively. Thus, with the increase of drought occurrence times, the average increase rate of precipitation frequency from large to small is followed by heavy rainstorm and rainstorm, while heavy rain and moderate rain decrease slightly. The patterns of the heavy precipitation that occurred in areas such as Beijing and Tianjin in 2012 are consistent with the results of this study.

The drought occurrence times in area II grows slightly, at a rate of $1.98 \%$. With the increase of drought occurrence times, the average increase rate of precipitation frequencies in different intensities show an increasing trend, in which the respective average increase rates of moderate rain, heavy 
rain, rainstorm, heavy rainstorm and extraordinary rainstorm are $3.71,5.46,8.11,14.09$ and $50.00 \%$. Thus, with the increase of drought occurrence times, the average increase rate of precipitation frequency from large to small is followed by extraordinary rainstorm, heavy rainstorm and rainstorm, while heavy rain and moderate rain do not show particularly significant increases.

The drought occurrence times in area III grows by $2.73 \%$. While the heavy rainstorm and extraordinary rainstorm frequencies show decreasing trends with the increase of drought times (with respective average increase rates of -6.25 and $-16.67 \%$ ), the other types show small increasing trends, in which the respective average increase rates of moderate rain, heavy rain and rainstorm frequency is $2.09,5.72$ and $2.84 \%$. Thus, it may be seen that with the increase of drought occurrence times, the change trends of each precipitation frequency in abrupt drought-flood change prone areas are not significant.

The drought occurrence times in area IV grows by $7.6 \%$. With the increase of drought occurrence times, the average increase rate of precipitation frequency from moderate rain to extraordinary rainstorm is not significant, at about $5 \%$. Due to the fact that this area is a temperate continental climate located in the inland, it is not conducive to the formation of extremely heavy precipitation.

The drought occurrence times in area $\mathrm{V}$ grows significantly, by $12.46 \%$. While moderate rain frequency shows a decreasing trend with the increase of drought times (at an average increase rate of $-3.85 \%$ ), the others show increasing trends, in which the respective average increase rates of heavy rainstorm, rainstorm and heavy rain frequency are $84.76,30.48$ and $7.47 \%$. Thus it may be concluded that with the increase of drought occurrence times, the extremely strong precipitation types of rainstorm and heavy rain show significant increasing trends, while extraordinary rainstorms do not occur, and moderate rain and heavy rain show no clear changes. This area is located in the Fen-Wei Valley basin, which is conducive for the formation of terrain strong precipitation processes.

The drought occurrence times in area VI grows by $3.37 \%$. While moderate rain frequency shows an increasing trend with the increase of drought times (at the average increase rate of $7.61 \%$ ), the other types show decreasing trends, in which the respective average increase rates of heavy rainstorm, heavy rain and moderate rain frequencies are -53.13 , -24.25 and $-3.05 \%$ respectively. Thus, with the increase of drought occurrence times, the extremely strong precipitation rate becomes lower.

The drought occurrence times in area VII grows by $5.96 \%$. While the moderate rain frequency shows a decreasing trend with the increase of drought times (at the average increase rate of $-5.36 \%$ ), the other types show increasing trends, in which the respective average increase rates of heavy rainstorm, heavy rain and moderate rain frequency are $112.50,43.45$ and $7.73 \%$. Thus, with the increase of drought occurrence times, the heavy rainstorm and rainstorm frequencies become higher, while those of heavy rain and moderate rain frequency are not significant.

In general, drought occurrence times shows an increasing trend in the Huang-Huai-Hai River basin from 19612011, but the drought times increase range differs among the seven subareas, among which areas IV and V, namely the region including the Hetao Plains in Ningxia-Inner Mongolia, Inner Mongolia and Loess plateaus and Fen-Wei Valley area, the drought occurrence times show significant increasing trends, with the respective average increase rates at about $10 \%$ higher than those of the 1960s. Those of the other subareas are not significant, at about $5 \%$. With the increase of drought times, the probability of each precipitation intensity change becomes complicated. Areas I and II are located in the eastern coastal areas, and are thus more vulnerable to extremely strong precipitation with the increase of drought times, while areas III and IV, located in the inland area, are not prone to strong precipitation. Area $\mathrm{V}$, located in the river valley area, is prone to short durations of strong precipitation, influenced by its small local topography, but the formation process is relatively complex. Areas VI and VII, located in the plateau mountain climate region, do not easily experience extremely strong precipitation, due to their high altitude, complex topography and the lower annual precipitation variation.

\section{Conclusions}

In recent years, extreme weather events, such as alternating droughts and floods, sharp transitions between droughts and floods, and floods following extreme droughts, have been a research hotspot. This paper takes the Huang-Huai-Hai River basin as the research object, analyzes the change relationship between drought occurrence times and precipitation intensity for different drought magnitudes and different years, based on the daily precipitation data from 171 stations for the years 1961-2011. From the study results, the following conclusions are drawn:

1. Drought occurrence times with different magnitudes in each subarea of the basin show increasing trends, and the interdecadal changes are not significant, but the spatial differences are large. Severe and extraordinary droughts are more common in northern China (area I), on the Hetao Plains in Ningxia-Inner Mongolia, on the Inner Mongolia and Loess plateaus and in the FenWei Valley area (areas IV and V); light and moderate droughts are more common in the Huai River basin and on the Hai River basin piedmont plains (areas II and III).

2. With the increase of drought magnitude, the probability of extraordinary rainstorm is lower, but the spatial variation differs with diverse precipitation intensity. With the increase of drought magnitude, the areas surrounding 
Bo Sea, the Shandong Peninsula and the Huai River downstream, the probabilities of different precipitation intensities first show decreasing trends. When droughts continue to develop and form extraordinary droughts, the probabilities of different precipitation intensities are increased. This situation indicates that strong precipitation occurs after continuous drought; with the increase of drought magnitude the probabilities of different precipitation intensities show decreasing trends in the upper and middle reaches of the Huai River, on the Hai River basin piedmont plains, Hetao Plains in Ningxia-Inner Mongolia, on the Inner Mongolia and Loess plateaus and in the Fen-Wei Valley area. The probability of each precipitation intensity change is complicated in the high-altitude mountain hills and on the Tibetan Plateau.

3. With the increase of drought times, areas I, II and V, located on the coast and in the valley or basin, are more vulnerable to the formation of extremely strong precipitation, while areas III, IV, VI and VII, located in the inland area, do not easily form extremely strong precipitation.

4. This paper only analyzes the changes of different drought degrees and the change characteristics of first precipitation intensity after drought. The formation of precipitation is closely related to several factors, such as the mesoscale weather system, atmospheric circulation movement, underlying surface factors of local terrain and vegetation cover, and so on, which are common results of the interaction of multiple factors and its mechanisms are very complex, therefore further indepth study of the causes of their formation is still required.

Acknowledgements. This work is supported by the Foundation for the State Key Development Program for Basic Research of China (grant no. 2010CB951102), Innovative Research Groups of the National Natural Science Foundation of China (grant no. 51021106), and National Natural Science Foundation of China (grant no. 51009150).

Edited by: A. Opere

\section{References}

Cancelliere, A., Mauro, G. D., Bonaccorso, B., and Rossi, G.: Drought forecasting using the Standardized Precipitation Index, Water Resour. Manage., 21, 801-819, 2007.

Cheng, Z., Xu, M., Luo, L. S., and Ding, X. J.: Climate characteristics of drought-flood abrupt change events in Huai River basin, J. China Hydrol., 32, 73-79, 2012 (in Chinese).

Dai, A., Trenberth, K. E., and Qian, T. T.: A global dataset of Palmer Drought Severity Index for 1870-2002: relationship with soil moisture and effects of surface warming, J. Hydrometeorol., 5, 1117-1130, 2004.

Feng, P., Wang, Z. J., and Yang, P.: Analysis on the drought character of Hai River basin, Water Resour. Hydropower Engin., 34, 33-35, 2003 (in Chinese).

Gu, Y. X., Brown, J. F., Verdin, J. P., and Wardlow, B.: A five-year analysis of MODIS NDVI and NDWI for grassland drought assessment over the central Great Plains of the United States, Geophys. Res. Lett., 34, L06407, doi:10.1029/2006GL029127, 2007.

Kohonen, T.: Self-Organizing Maps, 3rd Edn., Berlin: SpringerVerlag, 2001.

Łabędzki, L.: Estimation of local drought frequency in central Poland using the standardized precipitation index SPI, Irrig. Drain., 56, 67-77, 2007.

Marengo, J. A., Jones, R., Alves, L. M., and Valverde, M. C.: Future change of temperature and precipitation extremes in South America as derived from the PRECIS regional climate modeling system, Int. J. Climatol., 29, 2241-2255, 2009.

Murthy, C. S., Sesha Sai, M. V. R., Bhanuja Kumari, V., and Roy, P. S.: Agricultural drought assessment at disaggregated level using AWiFS/WiFS data of Indian Remote Sensing satellites, Geocarto Int., 22, 127-140, 2007.

Narasimhan, B. and Srinivasan, R.: Development and evaluation of soil moisture deficit index (SMDI) and evapotranspiration deficit index (ETDI) for agriculture drought monitoring, Agr. Forest Meteorol., 133, 69-88, 2005.

Palmer, W. C.: Meteorological drought, Research Paper 45, US Dept. of Commerce, Weather Bureau, Washington D.C., 58 pp., 1965.

Parry, M. L., Canziani, O. F., Palutikof, J. P., van der Linden, P. J., and Hanson, C. E. (Eds.): Climate Change 2007: Impacts, Adaptation and Vulnerability, Contribution of Working Group II to the Fourth Assessment Report of the Intergovernmental Panel on Climate Change, Cambridge University Press, Cambridge, UK, 982 pp., 2007.

Parthasarathy, B., Sontakke, N. A., Monot, A. A., and Kothawale, D. R.: Droughts/floods in the summer monsoon season over different meteorological subdivisions of India for the period 18711984, Int. J. Climatol., 7, 57-70, 1987.

Peng, G. H., Xia, J., Ma, X. F., and Ma, J. Q.: Analysis on drought frequency distribution and digital characteristics of number of turns of the Yellow River basin, Yellow River, 33, 3-5, 2011 (in Chinese).

Shao, X. M., Yan, C. R., and Wei, H. B.: Spatial and temporal structure of precipitation in the Yellow River basin based on Kriging method, Chinese J. Agrometeorol., 27, 65-69, 2006 (in Chinese).

Tang, M., Shao, D. G., and Yao, C. L.: Causes and countermeasures of sudden changing from drought to waterlogging in Huaibei region, J. China Inst. Water Resour. Hydropower Res., 5, 26-32, 2007 (in Chinese).

Wang, S., Tian, H., Ding, X. J., Xie, W. S., and Tao, Y.: Climate characteristics of precipitation and phenomenon of drought-flood abrupt alternation during main flood season in Huai River basin, Chinese J. Agrometeorol., 30, 31-34, 2009 (in Chinese).

Xiao, J. X., Mu, B., and Hu, F.: Agricultural meteorology, Higher Education Press, Beijing, p. 93, 2009 (in Chinese).

Yang, Z. H. and Yang, Y.: Research and development of selforganizing maps algorithm, Comput. Eng., 32, 201-228, 2006 (in Chinese). 
Zhai, L. X. and Feng, Q.: Dryness/wetness climate variation based on standardized precipitation index in Northwest China, J. Nat. Resour., 26, 847-857, 2011 (in Chinese).

Zhang, P., Wang, F. H., Wu, Z. L., and Zhu, Z.: Analysis on the climatic laws of drought-flood abrupt change in the Huaibei City, Express Water Resour. Hydropower Inf., 29, 139-140, 2008 (in Chinese).

Zhang, Q., Xu, C. Y., and Zhang, Z. X.: Observed changes of drought/wetness episodes in the Pearl River basin, China, using the standardized precipitation index and aridity index, Theor. Appl. Climatol., 98, 89-99, 2009.
Zhao, L., Wu, J. J., Lü, A. F., Liu, X. L., and Liu, M.: Spatial and temporal analysis of drought over the Huang-Huai-Hai Plain and its surroundings based on the Standardized Precipitation Index, Resour. Sci., 33, 468-476, 2011 (in Chinese).

Zhou, L. Y., Wang, Y. Q., Ma, J. X., Zhang, L., and Fan, S. Y.: Numerical study on the mechanism of summer flood and drought in Northern Northeast China, J. Nanjing Institute Meteorol., 24, 127-136, 2001 (in Chinese). 